\title{
EFFECT OF THE MULTIPLE DAMAGES AND TEMPERATURE CHANGES ON THE NATURAL FREQUENCY
}

\author{
Sattar Mohammadi Esfarjani, Mehdi Salehi, Aazam Ghassemi \\ Department of Mechanical Engineering, Najafabad Branch, Islamic Azad University, Najafabad, Iran \\ e-mail: satar.iran@gmail.com (corresponding author); mehdi.salehi@pmc.iaun.ac.ir; a_ghassemi@pmc.iaun.ac.ir
}

\begin{abstract}
Damage detection based on structural dynamic characteristics, such as natural frequencies and mode shapes, is an important area of research. Obtaining accurate structural dynamic characteristics is perhaps the most challenging aspect. In particular, changes in environmental temperature due to seasonal weather or radiation from sunshine leads to changes in the dynamic characteristics of structures. An important conclusion is that changes in the dynamic characteristics of a structure due to damage may be smaller than changes in the dynamic characteristics due to variations in temperature. Also, damage can affect the frequency response. This is the first study of evaluation of the effect of changes in temperature and multiple damages on natural frequency at the same time. In this paper, the simultaneous effect of the multiple defects and temperature on the natural frequencies of 6063 aluminum alloy beam are assessed numerically. ABAQUS finite element software is used for the numerical analysis. The present paper aims to evaluate the temperature effect and multiple damages on vibration responses. The variations in the frequency have been analysed in simulation by using an aluminum specimen and obtaining impedance signatures at temperatures ranging from $-200^{\circ} \mathrm{C}$ to $204^{\circ} \mathrm{C}$. The results show that an increase in temperature leads to a decrease in structural frequency, and that a decrease in temperature leads to an increase in structural frequency. The evaluation of the effect of multiple defects on natural frequency shows that when damages are created in the structure, there is a significant decrease in the natural frequency responses of the 6063 aluminum alloy beam. The results show that damage causes a decrease in the natural frequency of the structure. This study highlights the importance of applying simulation methods to the evaluation of the effect of changes in environmental temperature and multiple damages on the dynamic characteristics such as natural frequencies and mode shapes, especially at the same time.
\end{abstract}

Keywords: structural health monitoring, damage detection, vibration response, temperature, natural frequency

\section{Introduction}

Many techniques have been proposed to detect and localize structural damage using changes in dynamic characteristics of structures such as natural frequency and mode shape (Xu and $\mathrm{Wu}$, 2007). Modal parameters such as natural frequencies and mode shapes are sensitive indicators of structural damage. However, they are not only sensitive to damage, but also to environmental conditions such as humidity, wind and, most important, temperature (Meruane and Heylen, 2012). In particular, changes in environmental temperature due to seasonal weather or radiation from sunshine lead to changes in the dynamic characteristics of structures. An important conclusion is that the changes in dynamic characteristics of the structure due to damage may be smaller than changes in the dynamic characteristics due to variations in temperature (Ralbovsky et al., 2014). For large structures, such as long-span bridges, damage detection is affected by environmental factors. Significant damage may cause very small changes in dynamic characteristics, and these changes may go undetected due to changes in environmental and operational 
conditions. These changes have an influence on the dynamic characteristics of the structure. Damage induced dynamic characteristics may be completely masked by changes in dynamic characteristics due to changes in environmental temperature (Xu and $\mathrm{Wu}, 2007$ ).

The effect of crack location in the modal frequency of a draft gear used in auto couplers of freight railway wagon for various orientations was investigated by Harak et al. (2015). They showed that the defect in consecutive pads causes more changed in frequency as compared to a single defective pad. As far as the location of the defective pad is concerned, it is seen that the draft gear frequency is more sensitive to defective pads located either near the housing base plate or top follower (Harak et al., 2015). The effects of crack ratios and positions on the fundamental frequencies and buckling loads of slender cantilever Euler beams with a singleedge crack are investigated by Karaag̃aç et al. (2009). Sayman et al. (2013) presented the effect of interface crack on the free vibration response of a sandwich composite beam experimentally and numerically. They showed that the natural frequency of the torsional mode decreases as the crack length increases (Sayman et al., 2013). The effect of temperature on damage detection results was detected early. Eigenfrequency changes caused by temperature effects on different structures were described in the works of Peeters and DeRoeck (2001), Farrar et al. (1997) or Ralbovsky et al. (2010). The effect of temperature was considered as an obstacle for damage detection. Various methods for removing that effect were proposed, for example in the works of DeRoeck et al. (2000), Hu et al. (2012) and many other scientists (Ralbovsky et al., 2010). Variations in frequencies are caused mainly by a change in the modulus of a material under different temperatures. Modal frequencies of steel structures, the aluminum beam, and the RC structures decrease by about $0.02,0.03$, and $0.15 \%$, respectively, when temperature increases by one degree Celsius, regardless of modes and structural types. Frequencies of concrete structures are more sensitive to temperature changes than metallic structures (Xia et al., 2012).

The present paper aims to evaluate the temperature effect and multiple damages on vibration responses. In this study, the frequency changes of a structure caused by multiple defects and temperature changes in the 6063 aluminum alloy beam are studied. The thermally induced changes in dynamic characteristics are compared with those due to damages to the 6063 aluminum alloy beam. The changes caused by temperature have been analyzed based on the following aspects: (1) change of the passion rate of the aluminum alloy; (2) changes of the elastic modulus of the aluminum alloy. Guidelines to predict changes in the frequency and mode shape curvature due to temperature changes in the aluminum alloy have been obtained, which is useful for design purposes $(\mathrm{Xu}$ and $\mathrm{Wu}, 2007)$. The remainder of the paper is organized as follows. In Section 2, theory of the temperature effect on natural frequency is discussed. Section 3 is devoted to the process of the evolution effect of multiple defects and temperature changes on structural natural frequency responses. The verification and simulation of the method is discussed in Section 4. Numerical methods and results for evaluation of the temperature effect and multiple damages on vibration responses are presented in Section 5. The conclusion is reported in Section 6.

\section{Theory}

Let us consider a rectangular plate which is subjected to an exponential temperature distribution along the length, i.e. in the $x$-direction (Arun et al., 2014)

$$
T=T_{0} \frac{e-e^{x}}{e-1}
$$

where $T$ denotes the temperature excess above the reference temperature at any point at the distance $X=x / a$ and $T_{0}$ denotes the temperature excess above the reference temperature at 
the end, i.e. $x=a$ or $X=1$. The temperature dependence of the modulus of elasticity for most of engineering materials is given by Nowacki (1962), (Arun et al., 2014)

$$
E(T)=E_{0}(1-\gamma T)
$$

where $E_{0}$ is the value of Young's modulus at the reference temperature, i.e. $T=0$, and $\gamma$ is the slope of variation of $E$ with $T$ (Arun et al., 2014). Taking as the reference temperature, the temperature at the end of the plate, i.e. at $X=1$, the modulus variation in view of (2.1) and (2.2) becomes (Arun et al., 2014)

$$
E(X)=E_{0}\left(1-\alpha \frac{e-e^{X}}{e-1}\right)
$$

where $\alpha=\gamma T_{0}(0-\alpha<1)$ is a constant known as the temperature constant. In the above literature, most studies show that an increase in temperature leads to a decrease in structural frequencies, while magnitude varies depending on structures, materials, and temperature range. Variations in natural frequencies of structures with temperature are caused by changes in material properties, in particular, the modulus of elasticity. To quantify the effect of temperature on natural frequencies, a single-span or multi-span prismatic beam made of an isotropic material is used as an example. Its undamped flexural vibration frequency of the order $n$ is (Xia et al., 2012; Blevins, 1979)

$$
f_{n}=\frac{\lambda_{n}^{2}}{2 \pi l^{2}} \sqrt{\frac{E I}{\mu}}
$$

where $\lambda_{n}$ is a dimensionless parameter and is a function of boundary conditions, $l$ is length of the beam, $\mu$ is mass per unit length, $E$ is the modulus of elasticity, and $I$ is the moment of inertia of cross-sectional area. It is assumed that variations in temperature do not affect mass and boundary conditions, but only geometry of the structure and mechanical properties of the material.

\section{Description of the process of the evolution effect of multiple defects and temperature changes on structural natural frequency responses}

In recent years, the use of simulation models to develop vibration based damage detection techniques has become very popular, because it is a less expensive and time-consuming procedure than investigation of real structures or experimental models. Also, an experimental setup is also a fairly difficult process. Since the Finite Element (FE) method has been widely accepted as an analysis tool in Structural Health Monitoring (SHM), the above mentioned constraints can be overcome by using a validated FE model to simulate the real structure (Moragaspitiya et al., 2013). In this Section, a FE modeling method is used to obtain natural frequencies of the structure. FE models of the sample are developed utilizing the commercial FE package ABAQUS. As shown in Fig. 1, natural frequency responses of the structure are obtained from FE modeling of the intact and damaged structure. Then, the natural frequency responses of the structure are obtained for varying temperatures from $-200^{\circ} \mathrm{C}$ to $204^{\circ} \mathrm{C}$. This is illustrated in Fig. 2 .

\section{Numerical simulation}

In this Section, evaluation of the effect of multiple defects on natural frequencies of the 6063 aluminum alloy beam is discussed. Then, the effect of temperature changes on the natural frequencies of the 6063 aluminum alloy beam is investigated as well. 


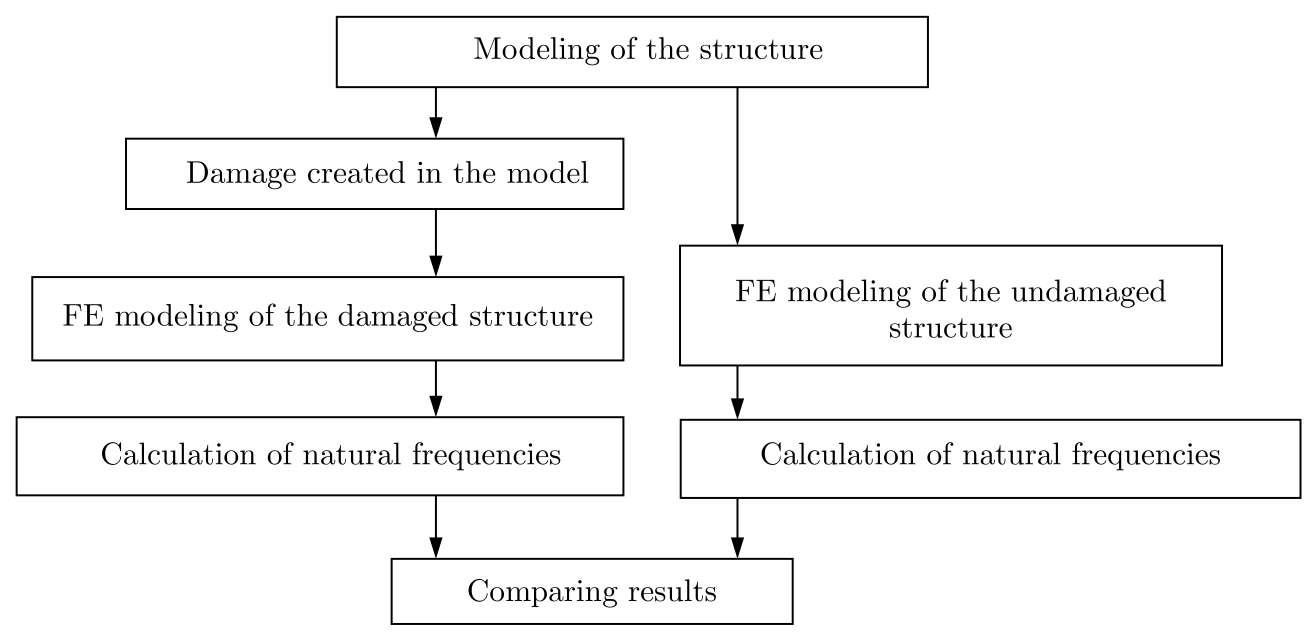

Fig. 1. Flowchart of the evolution effect of multiple defects on the natural frequency responses

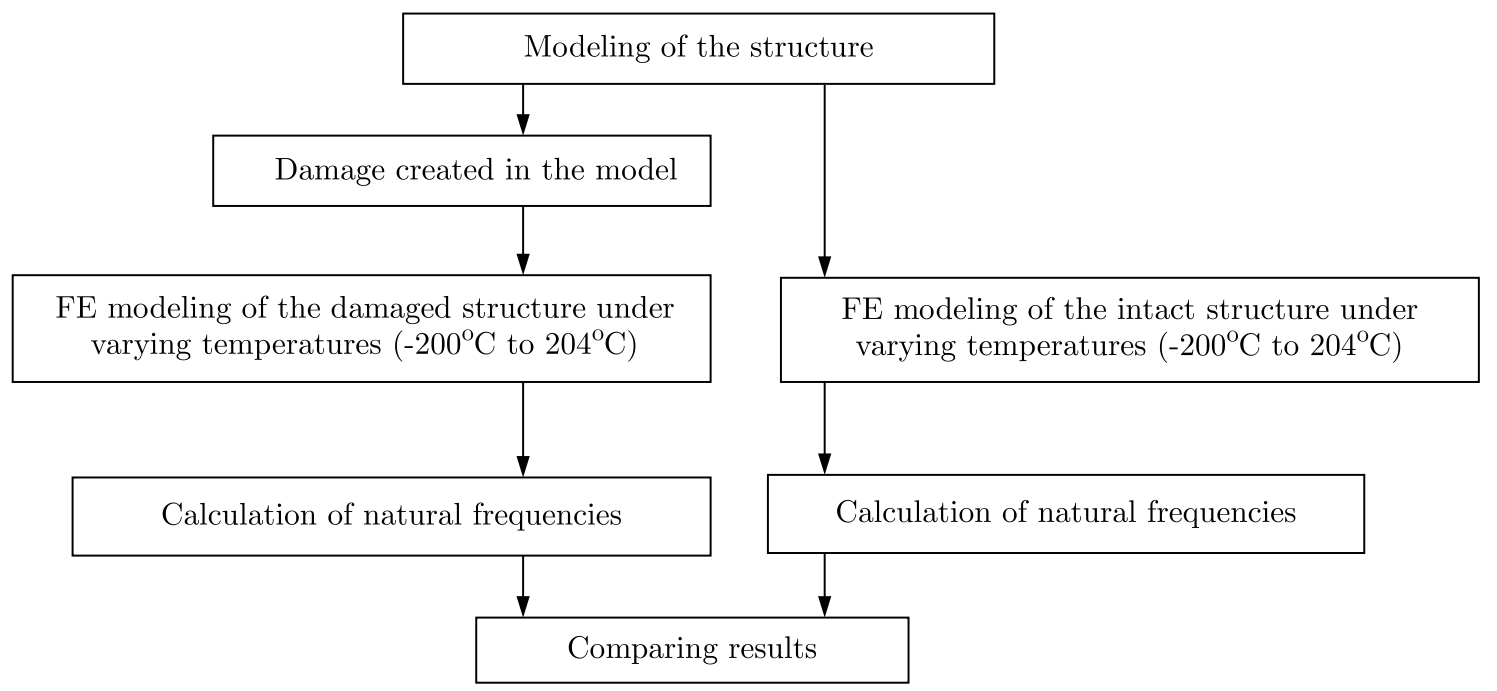

Fig. 2. Flowchart of the evolution effect of temperature changes on the natural frequency responses of the undamaged structure

\subsection{Evaluation of the effect of multiple defects on natural frequencies}

A 3-D FE model of the 6063 aluminum alloy beam has been created using ABAQUS (see Fig. 3). The overall dimensions of the beam are $400 \mathrm{~mm} \times 40 \mathrm{~mm} \times 0.16 \mathrm{~mm}$. The material properties are listed in Table 1. The clamped end of the beam has no rotation or displacement in any direction (see Fig. 4). Finally, the model is analysed with a frequency step, and the natural frequency responses for 10 modes are obtained from the results. As shown in Fig. 5, in order to investigate the effect of multiple defects on natural frequencies, several damage scenarios are simulated. Two types of damages are simulated (Table 2) and each is introduced using different extents to investigate the effect of multiple defects on natural frequencies. Free meshing is more suitable on the damaged section, thus free meshing with triangular and tetrahedral elements is utilized (see Fig. 6). The elements type, the total number of elements and nodes for the undamaged model and damage scenarios that are created in the model are shown in Table 3 . In each step, the damaged model is analysed with a frequency step of the natural frequency responses 
for 10 modes obtained from the results. Figure 7 shows the results of calculating the structural response to various damage cases to investigate the effect of multiple defects on natural frequencies. As shown in Fig. 7, when damages are created in the structure, the natural frequencies responses of the 6063 aluminum alloy beam significantly decrease. The results show that the damage decreases the natural frequency of the structure.

Table 1. Material properties of the 6063 aluminum alloy beam

\begin{tabular}{|c|c|c|}
\hline $\begin{array}{c}\text { Density } \\
\rho[\mathrm{g} / \mathrm{cc}]\end{array}$ & $\begin{array}{c}\text { Poisson's ratio } \\
\nu[-]\end{array}$ & $\begin{array}{c}\text { Modulus of elasticity } \\
E[\mathrm{GPa}]\end{array}$ \\
\hline \hline 2.7 & 0.33 & 68.9 \\
\hline
\end{tabular}

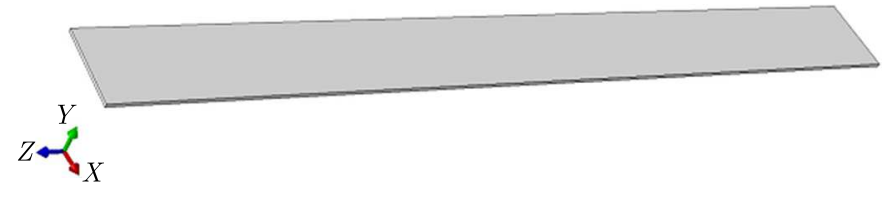

Fig. 3. A FE model of the beam created using ABAQUS

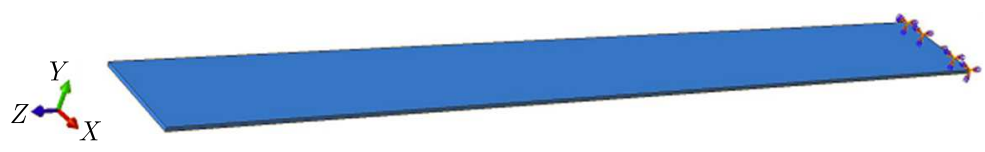

Fig. 4. Boundary conditions

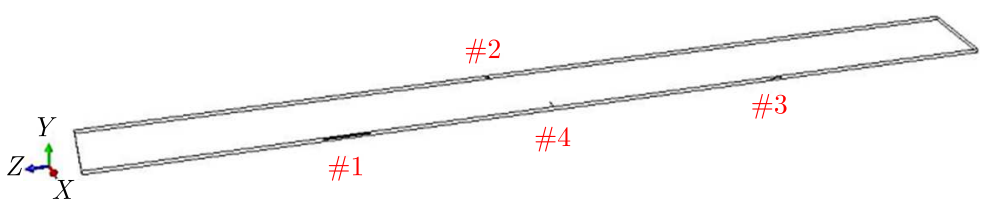

Fig. 5. Location of damages in the model

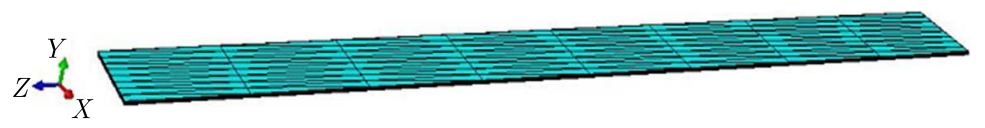

Fig. 6. Free meshing technique with linear tetrahedral and hexahedral elements

Table 2. Introduced damage types to investigate the effect of multiple defects on the natural frequency

\begin{tabular}{|c|c|c|c|}
\hline Damage & Description & $\begin{array}{c}\text { Dimensions } \\
{[\mathrm{mm}]}\end{array}$ & $\begin{array}{c}\text { Location } \\
{[\mathrm{mm}]}\end{array}$ \\
\hline \hline$\# 1$ & delamination in the beam & $20 \times 0.06 \times 1$ & $100-120$ \\
\hline$\# 2$ & delamination in the beam & $2 \times 0.02 \times 0.5$ & $180-182$ \\
\hline$\# 3$ & delamination in the beam & $5 \times 0.02 \times 0.077$ & $300-305$ \\
\hline$\# 4$ & transverse crack in the beam & $0.02 \times 0.17 \times 5$ & $200-200.02$ \\
\hline
\end{tabular}


Table 3. The type of elements, the total number of elements and nodes for undamaged model and damage scenarios that were created in the model

\begin{tabular}{|c|c|c|c|}
\hline Structure status & $\begin{array}{c}\text { Total number } \\
\text { of nodes }\end{array}$ & $\begin{array}{c}\text { Total number } \\
\text { of elements }\end{array}$ & Type of elements \\
\hline \hline Undmaged model & 49323 & 32000 & $\begin{array}{c}\text { linear hexahedral elements } \\
\text { of type C3D8R }\end{array}$ \\
\hline $\begin{array}{c}\text { Damage scenario } \\
\# 1\end{array}$ & 49838 & 195122 & $\begin{array}{c}\text { linear tetrahedral elements } \\
\text { of type C3D4 }\end{array}$ \\
\hline $\begin{array}{c}\text { Damage scenario } \\
\# 2\end{array}$ & 98536 & 383130 & $\begin{array}{c}\text { linear tetrahedral elements } \\
\text { of type C3D4 }\end{array}$ \\
\hline $\begin{array}{c}\text { Damage scenario } \\
\# 3\end{array}$ & 147420 & 572781 & $\begin{array}{c}\text { linear tetrahedral elements } \\
\text { of type C3D4 }\end{array}$ \\
\hline $\begin{array}{c}\text { Damage scenario } \\
\# 4\end{array}$ & 196712 & 763944 & $\begin{array}{c}\text { linear tetrahedral elements } \\
\text { of type C3D4 }\end{array}$ \\
\hline
\end{tabular}

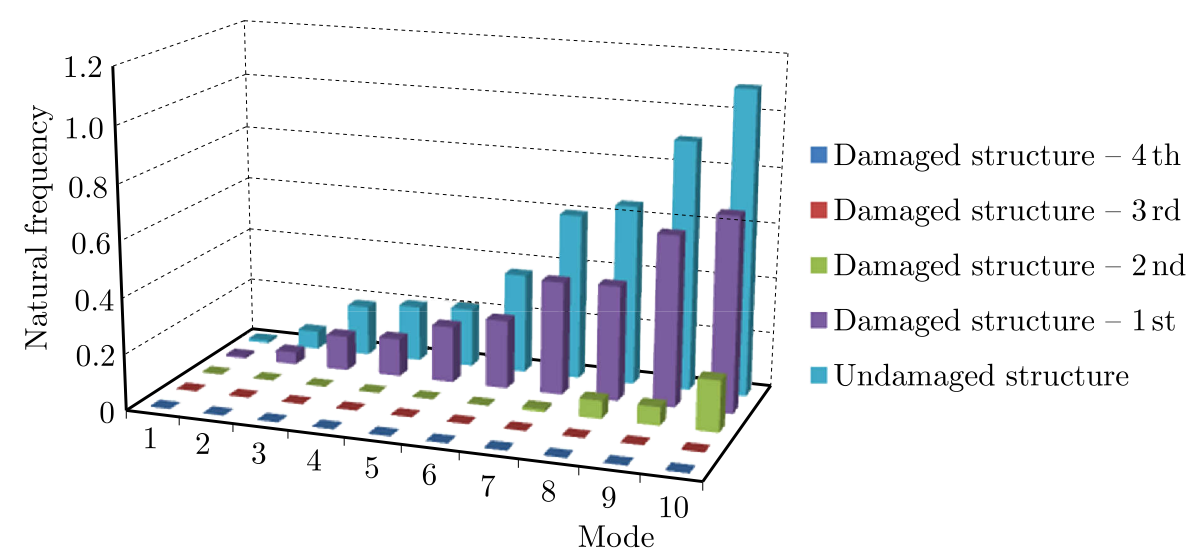

Fig. 7. Effect of multiple defects on natural frequency responses of the 6063 aluminum alloy beam

\subsection{Investigation of the effect of temperature changes on natural frequencies}

The investigation of the effect of temperature changes on natural frequencies is presented in this Section. For the purpose of this investigation, two types of scenarios are simulated to identify the effect of temperature changes on the natural frequencies (Table 4). The first type of scenario,

Table 4. Introduced damage types to investigate the effect of temperature changes on the natural frequency

\begin{tabular}{|l|c|}
\hline \multicolumn{1}{|c|}{ Structure status } & Description \\
\hline \hline First type of scenario: & intact structure, \\
undmaged model $\# 1$ & investigate at $-200^{\circ} \mathrm{C}$ to $204^{\circ} \mathrm{C}$ \\
\hline $\begin{array}{l}\text { Second type of scenario: } \\
\text { damaged model } \# 2\end{array}$ & $\begin{array}{c}\text { damaged structure with transverse crack, } \\
\text { investigate at }-200^{\circ} \mathrm{C} \text { to } 204^{\circ} \mathrm{C}\end{array}$ \\
\hline
\end{tabular}

the intact model, is analysed with some frequency step, and the natural frequency responses for 10 modes are obtained. For the second type of scenario, a transverse crack is created on the model (see Fig. 8). The size of the transverse crack is $5 \mathrm{~mm} \times 0.17 \mathrm{~mm} \times 0.02 \mathrm{~mm}$, and is located at a distance of $200 \mathrm{~mm}$ to $200.02 \mathrm{~mm}$ from the fixed end. Then, the damaged model is analysed and the natural frequency responses for 10 modes are obtained. Tables 5 and 6 show respectively the 
results of calculation of the undamaged and damaged structural response to various temperature cases presenting the effect of temperature on the natural frequency. Figures 9 and 10 respectively show the effect of temperature changes on natural frequency responses pertaining to undamaged and damaged structures. The results show that as temperature of the structure increases, the natural frequencies responses of the structure decrease.

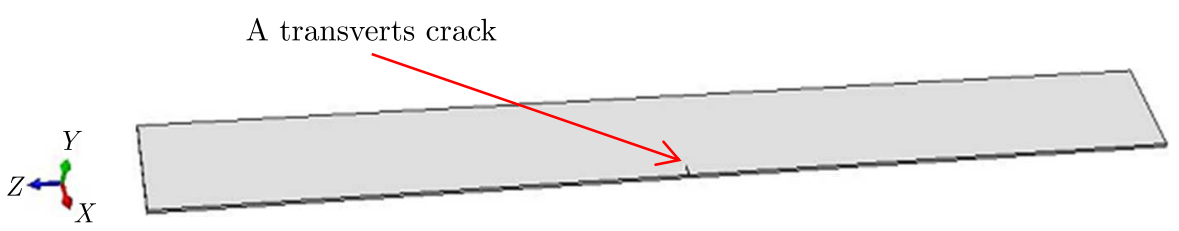

Fig. 8. Transverse crack created in the model

Table 5. Effect of temperature changes on the natural frequency responses of the undamaged structure

\begin{tabular}{|c|c|c|c|c|c|c|c|}
\hline \multirow{2}{*}{ Mode } & \multicolumn{6}{|c|}{ Natural frequencies $\omega[\mathrm{rad} / \mathrm{s}]$} & and corresponding temperatures $t\left[{ }^{\circ} \mathrm{C}\right]$ \\
\cline { 2 - 8 } & $-200^{\circ} \mathrm{C}$ & $-129^{\circ} \mathrm{C}$ & $-73^{\circ} \mathrm{C}$ & $21^{\circ} \mathrm{C}$ & $93^{\circ} \mathrm{C}$ & $149^{\circ} \mathrm{C}$ & $204{ }^{\circ} \mathrm{C}$ \\
\cline { 2 - 8 } & $\omega[\mathrm{rad} / \mathrm{s}]$ & $\omega[\mathrm{rad} / \mathrm{s}]$ & $\omega[\mathrm{rad} / \mathrm{s}]$ & $\omega[\mathrm{rad} / \mathrm{s}]$ & $\omega[\mathrm{rad} / \mathrm{s}]$ & $\omega[\mathrm{rad} / \mathrm{s}]$ & $\omega[\mathrm{rad} / \mathrm{s}]$ \\
\hline \hline 1 & 0.00747343 & 0.00742029 & 0.00731643 & 0.00719205 & 0.0069961 & 0.00684871 & 0.00665982 \\
\hline 2 & 0.0468166 & 0.0464838 & 0.0458331 & 0.045054 & 0.0438264 & 0.042903 & 0.0417199 \\
\hline 3 & 0.131184 & 0.130251 & 0.128428 & 0.126245 & 0.122805 & 0.120218 & 0.116903 \\
\hline 4 & 0.143114 & 0.142097 & 0.140108 & 0.137726 & 0.133974 & 0.131151 & 0.127534 \\
\hline 5 & 0.212142 & 0.210634 & 0.207686 & 0.204156 & 0.198593 & 0.194408 & 0.189047 \\
\hline 6 & 0.257473 & 0.255643 & 0.252064 & 0.247780 & 0.241028 & 0.235950 & 0.229443 \\
\hline 7 & 0.426512 & 0.423480 & 0.417552 & 0.410455 & 0.399271 & 0.390858 & 0.380080 \\
\hline 8 & 0.431727 & 0.428658 & 0.422657 & 0.415473 & 0.404153 & 0.395637 & 0.384727 \\
\hline 9 & 0.638622 & 0.634082 & 0.625206 & 0.614579 & 0.597833 & 0.585236 & 0.569098 \\
\hline 10 & 0.727410 & 0.722239 & 0.712130 & 0.700025 & 0.680951 & 0.666603 & 0.648221 \\
\hline
\end{tabular}

Table 6. Effect of temperature changes on the natural frequency responses of the damaged structure

\begin{tabular}{|c|c|c|c|c|c|c|c|}
\hline \multirow{2}{*}{ Mode } & \multicolumn{6}{|c|}{ Natural frequencies $\omega[\mathrm{rad} / \mathrm{s}]$ and corresponding temperatures $t\left[{ }^{\circ} \mathrm{C}\right]$} \\
\cline { 2 - 8 } & $-200^{\circ} \mathrm{C}$ & $-129^{\circ} \mathrm{C}$ & $-73^{\circ} \mathrm{C}$ & $21^{\circ} \mathrm{C}$ & $93^{\circ} \mathrm{C}$ & $149^{\circ} \mathrm{C}$ & $204^{\circ} \mathrm{C}$ \\
\cline { 2 - 8 } & $\omega[\mathrm{rad} / \mathrm{s}]$ & $\omega[\mathrm{rad} / \mathrm{s}]$ & $\omega[\mathrm{rad} / \mathrm{s}]$ & $\omega[\mathrm{rad} / \mathrm{s}]$ & $\omega[\mathrm{rad} / \mathrm{s}]$ & $\omega[\mathrm{rad} / \mathrm{s}]$ & $\omega[\mathrm{rad} / \mathrm{s}]$ \\
\hline \hline 1 & 0.0111536 & 0.0110743 & 0.0109193 & 0.0107337 & 0.0104412 & 0.0102212 & 0.00993934 \\
\hline 2 & 0.0699099 & 0.0694129 & 0.0684413 & 0.0672779 & 0.0654448 & 0.0640658 & 0.0622991 \\
\hline 3 & 0.195750 & 0.194358 & 0.191637 & 0.188380 & 0.183247 & 0.179386 & 0.174439 \\
\hline 4 & 0.212484 & 0.210973 & 0.208020 & 0.204484 & 0.198912 & 0.194721 & 0.189352 \\
\hline 5 & 0.224307 & 0.222713 & 0.219595 & 0.215862 & 0.209981 & 0.205556 & 0.199888 \\
\hline 6 & 0.383982 & 0.381252 & 0.375916 & 0.369526 & 0.359457 & 0.351883 & 0.342180 \\
\hline 7 & 0.634711 & 0.630199 & 0.621377 & 0.610815 & 0.594172 & 0.581652 & 0.565613 \\
\hline 8 & 0.676172 & 0.671365 & 0.661967 & 0.650715 & 0.632985 & 0.619647 & 0.602560 \\
\hline 9 & 0.948804 & 0.942059 & 0.928872 & 0.913084 & 0.888204 & 0.869489 & 0.845512 \\
\hline 10 & 1.13783 & 1.12974 & 1.11393 & 1.09499 & 1.06516 & 1.04271 & 1.01396 \\
\hline
\end{tabular}




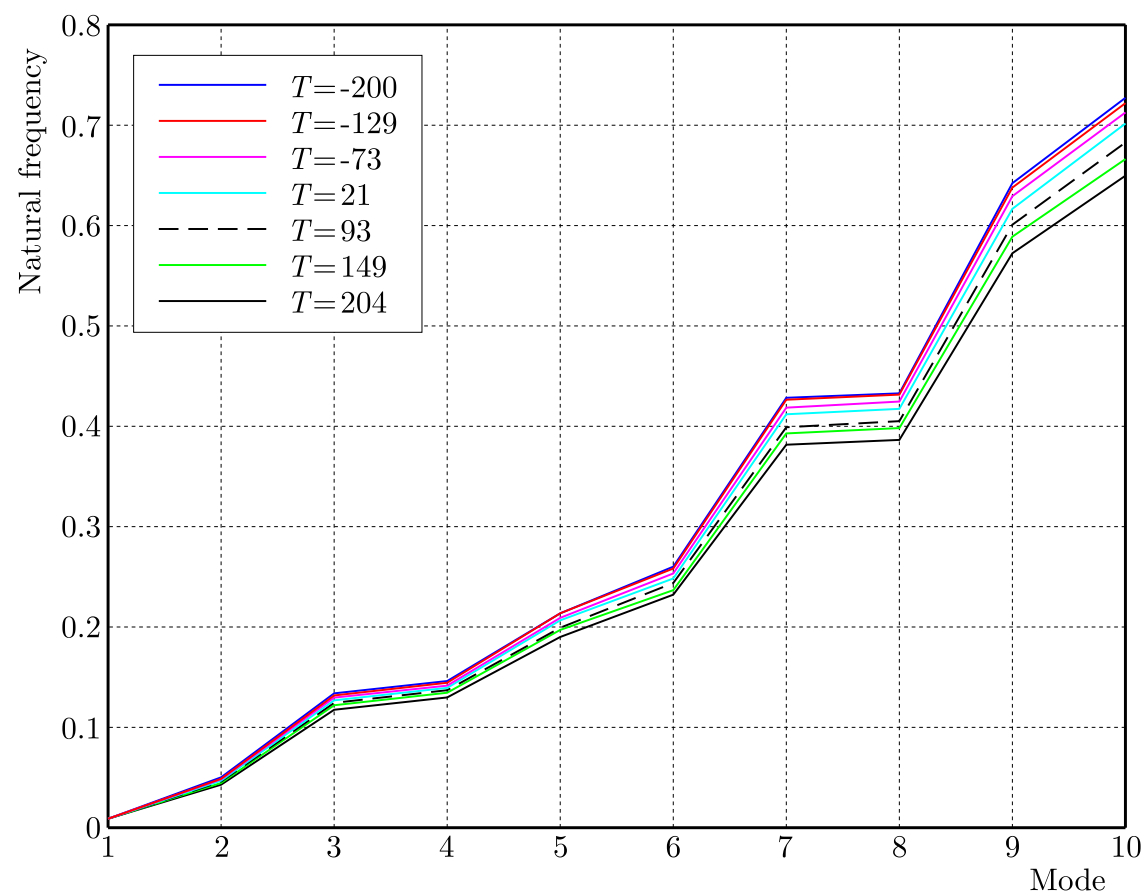

Fig. 9. Effect of temperature changes on the natural frequency for the undamaged structure

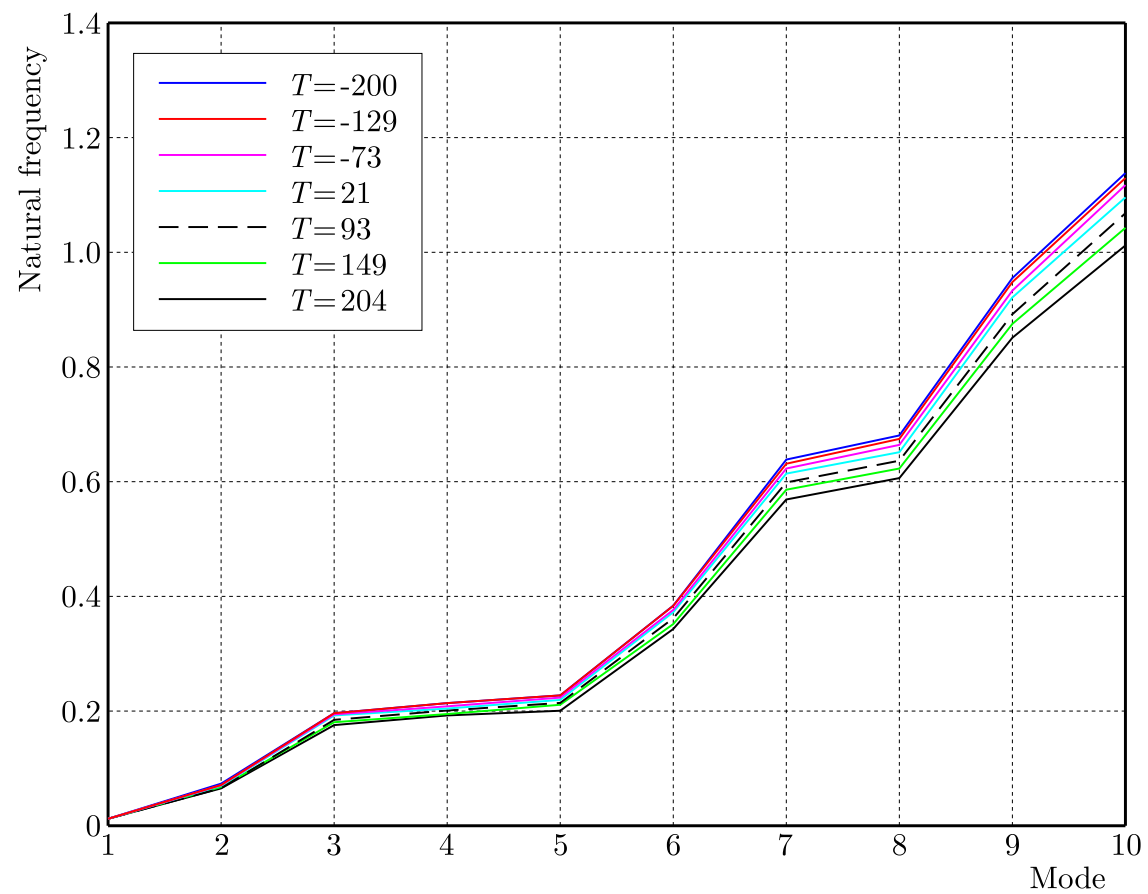

Fig. 10. Effect of temperature changes on the natural frequency for the damaged structure

\section{Conclusion}

This paper reviews multiple defects and the temperature effect on variations in modal properties of the structure. This is the first study of evaluation of the effect of temperature changes and multiple damages on the natural frequency at the same time. The variations in the frequency are analysed in simulation by using an aluminum specimen obtaining impedance signatures at temperatures ranging from $-200^{\circ} \mathrm{C}$ to $204^{\circ} \mathrm{C}$. The results show that an increase in temperature 
leads to a decrease in the structural frequency, and that a decrease in temperature leads to an increase in the structural frequency. Therefore, temperature effects are a critical problem for structural health monitoring based on vibration responses, especially in detecting low damage levels. Efficient compensatory methods for temperature effects remain to be developed. The evaluation of the effect of multiple defects on the natural frequency shows that when damages are created in the structure, there is a significant decrease in natural frequency responses of the 6063 aluminum alloy beam. The results show that damage causes a decrease in the natural frequency of the structure. This study highlights the importance of application of simulation methods to the evaluation the effect of changes in environmental temperature and multiple damages on dynamic characteristics, such as natural frequencies and mode shapes, especially taking place at the same time.

\section{References}

1. Arun K., Gupta, Mamta J., 2014, Exponential temperature effect on frequencies of a rectangular plate of non-linear varying thickness: a quinitic spline technique, Journal of Theoretical and Applied Mechanics, 52, 1, 15-24

2. Blevins R.D., 1979, Formulas for Natural Frequency and Mode Shape, Van Nostrand Reinhold, New York

3. DeRoeck G., Peeters B., Maeck J., 2000, Dynamic monitoring of civil engineering structures. Computational methods for shell and spatial structures, IASS-IACM, Athens, Greece

4. Farrar C.R., Doebling S.W., Cornwell P.J., Straser E.G., 1997, Variability of modal parameters measured on the Alamosa Canyon Bridge, Proceedings of 15th International Modal Analysis Conference, Orlando, USA, 1997, 257-263

5. Harak S.S, Sharma S.C., Shukla S., Gupta P., Kumar S., Harsha S.P., 2015, Effect of multiple location defects on the dynamics of draft gear used in freight railway wagon, International Journal of Vehicle Structures and Systems, 7, 3, 107-113

6. Hu W.H., Moutinho C., De Sa Caetano E., Magalhães F., Cunha A.A.M.F, 2012, Continuous dynamic monitoring of a lively footbridge for serviceability assessment and damage detection, Mechanical Systems and Signal Processing, 33, 38-55

7. KaraAĞaÇ C., ÖZturk H., SAbuncu M., 2009, Free vibration and lateral buckling of a cantilever slender beam with an edge crack: experimental and numerical studies, Journal of Sound and Vibration, 326, 235-250

8. Meruane V., Heylen W., 2012, Structural damage assessment under varying temperature conditions, Structural Health Monitoring, 11, 3, 345-357

9. Moragaspitiya P.H.N., Thambiratnam D.P., Perera N.J., Chan T.H.T., 2013, Development of a vibration based method to update axial shortening of vertical load bearing elements in reinforced concrete buildings, Engineering Structures, 46, 49-61

10. Peeters B., DeRoeck G., 2001, One-year monitoring of the Z24-Bridge: environmental effects versus damage events, Earthquake Engineering and Structural Dynamics, 30, 149-171

11. Ralbovsky M., Deix S., Flesch R., 2010, Frequency changes in frequency-based damage identification, Structure and Infrastructure Engineering, 6, 611-619

12. Ralbovsky M., Santos J., Kwapisz M., Dallinger S., Catarino J.M., 2014, Damage detection based on structural response to temperature changes and model updating, 7th European Workshop on Structural Health Monitoring, July 8-11, La Cité, Nantes, France

13. Sayman O.M., Toygar E., Kiral Z., Kiral B.G., 2013, Effect of the root crack on natural frequency of sandwitch composite beams, Pamukkale Üniversitesi Mühendislik Bilimleri Dergisi, 19, 7, 298-302 
14. Xia Y., Chen B., Weng S., Ni Y.-Q., Xu Y.-L., 2012, Temperature effect on vibration properties of civil structures: a literature review and case studies, Journal of Civil Structural Health Monitoring, 2, 29-46

15. Xu Z.-D., Wu Z., 2007, Simulation of the effect of temperature variation on damage detection in a long-span cable-stayed bridge, Structural Health Monitoring, 6, 177-189, DOI: $10.1177 / 1475921707081107$

Manuscript received November 3, 2016; accepted for print January 18, 2017 